\title{
Matrix Gla protein deficiency causes arteriovenous malformations in mice
}

\author{
Yucheng Yao, ${ }^{1}$ Medet Jumabay, ${ }^{1}$ Anthony Wang, ${ }^{1}$ and Kristina I. Boström ${ }^{1,2}$ \\ ${ }^{1}$ Division of Cardiology, David Geffen School of Medicine, and ${ }^{2}$ The Molecular Biology Institute, UCLA, Los Angeles, California, USA.
}

\begin{abstract}
Arteriovenous malformations (AVMs) in organs, such as the lungs, intestine, and brain, are characteristic of hereditary hemorrhagic telangiectasia (HHT), a disease caused by mutations in activin-like kinase receptor 1 (ALK1), which is an essential receptor in angiogenesis, or endoglin. Matrix Gla protein (MGP) is an antagonist of BMPs that is highly expressed in lungs and kidneys and is regulated by ALK1. The objective of this study was to determine the role of MGP in the vasculature of the lungs and kidneys. We found that $M g P$ gene deletion in mice caused striking AVMs in lungs and kidneys, where overall small organ size contrasted with greatly increased vascularization. Mechanistically, MGP deficiency increased BMP activity in lungs. In cultured lung epithelial cells, BMP-4 induced VEGF expression through induction of ALK1, ALK2, and ALK5. The VEGF secretion induced by BMP-4 in $\mathrm{Mgp}^{-/-}$epithelial cells stimulated proliferation of ECs. However, BMP-4 inhibited proliferation of lung epithelial cells, consistent with the increase in pulmonary vasculature at the expense of lung tissue in the $M g p$-null mice. Similarly, BMP signaling and VEGF expression were increased in $M g p^{-/-}$mouse kidneys. We therefore conclude that $M g p$ gene deletion is what we believe to be a previously unidentified cause of AVMs. Because lack of MGP also causes arterial calcification, our findings demonstrate that the same gene defect has drastically different effects on distinct vascular beds.
\end{abstract}

\section{Introduction}

Matrix Gla protein (MGP) is a small, gamma-carboxylated protein that binds and inhibits BMP-2 and BMP-4 (1-3). It is best known for its role as an inhibitor of arterial calcification; gene deletion of $\mathrm{Mgp}$ in mice results in transdifferentiation of aortic smooth muscle cells into osteochondrogenic lineage and extensive calcification in the aorta $(4,5)$. However, MGP is highly expressed in multiple organs, including lungs and kidneys, and excessive MGP in MgPtransgenic mice results in inhibition of the pulmonary vascular development (6). It has also been reported that patients with a deficiency of MGP, the so-called Keutel syndrome (7), have multifocal peripheral pulmonary artery stenoses (8), further supporting a role for MGP in vascular formation.

The activin-like kinase receptor 1 (ALK1) is essential for normal angiogenesis (9), and mutations in the Alk1 gene are known to cause hereditary hemorrhagic telangiectasia (HHT) $(10,11)$. HHT is characterized by arteriovenous malformations (AVMs) in organs, such as the lungs, intestine, and brain, and is associated with a high risk of potentially devastating bleeding. High levels of VEGF have been implicated in the pathogenesis of $\operatorname{HHT}(12,13)$, and we previously showed that BMP-9 stimulation of ALK1 has a suppressive effect on VEGF expression (14). We also showed that this suppression is accompanied by an induction of ALK5, which together with TGF- $\beta 1$ later overcomes the VEGF suppression (14). In absence of ALK1, this biphasic VEGF regulation does not function properly (14); instead, VEGF levels increase by an unidentified mechanism that does not appear to involve ALK5. Because ALK1 is induced by BMP-4, the ALK1/ALK5 pathway provides a means for BMP-4 to enhance VEGF. Thus, VEGF levels may be high due to increased BMP-4 activity or due to a deficiency in ALK1.

BMP-4 also induces MGP in ECs, an induction that is mediated by ALK1. The induction of MGP precedes that of ALK5 and VEGF

Conflict of interest: The authors have declared that no conflict of interest exists. Citation for this article: J Clin Invest. 2011;121(8):2993-3004. doi:10.1172/JCI57567.
(14), and MGP provides feedback inhibition for BMP-4 and ALK1 induction. In previous studies, we showed that, in absence of MGP, aortic VEGF expression increased due to increased BMP activity and induction of ALK1 and was associated with an abnormal endothelial response to inflammation (15). Because of the abnormal response and the increased VEGF expression, we hypothesized that lack of MGP may promote AVMs in MGP-expressing organs such as lungs and kidneys. In this study, we take advantage of MgPnull $\left(\mathrm{Mgp}^{--}\right)$mice and demonstrate a dramatic formation of AVMs in lungs and kidneys. Our results suggest that MGP deficiency is a previously unknown cause of AVMs and that vascular pathology due to MGP deficiency differs depending on the vascular bed.

\section{Results}

Abnormal vasculature and evidence of AVMs in lungs and kidneys from $M g \mathrm{P}^{-/-}$mice. To study the effects of altering MGP expression on vascular formation in lungs and kidneys, we compared the pulmonary and renal vasculature in 4-week-old $\mathrm{MgP}^{-/-}$mice with that of 4-week-old wild-type and $M g p$-transgenic $\left(M g p^{t g / w t}\right)$ mice. The phenotype caused by excess MGP is apparent in the heterozygous $M g p^{t g} / w t$ mice (6). For this reason, the heterozygous $M g p^{t g / w t}$ mice were used throughout the study because of high mortality in the $M g p^{t g} / t g$ mice (6). The $M g p^{-/-}$lungs and kidneys were slightly smaller than both wild-type and $M g p^{t g / w t}$ lungs and kidneys and appeared more vascularized when removed from the mice and after vascular casting (Figure 1A and Figure 2A, top 2 panels). We examined the vasculature using microcomputed tomography (micro CT), which revealed striking differences among the 3 mice. Images from the $3 \mathrm{D}$ analysis are shown in Figure 1A and Figure 2A (see also Supplemental Videos 1-6 for full reconstructions; supplemental material available online with this article; doi:10.1172/JCI57567DS1). The pulmonary and renal vasculature in $\mathrm{Mgp}^{-/-}$mice exhibited excessive branching of small vessels, irregular caliber of arteries, and evidence of AVMs, based on the increased visualization of the venous system, as compared with that of the wild-type and $M g p^{\operatorname{tg} / w t}$ mice 


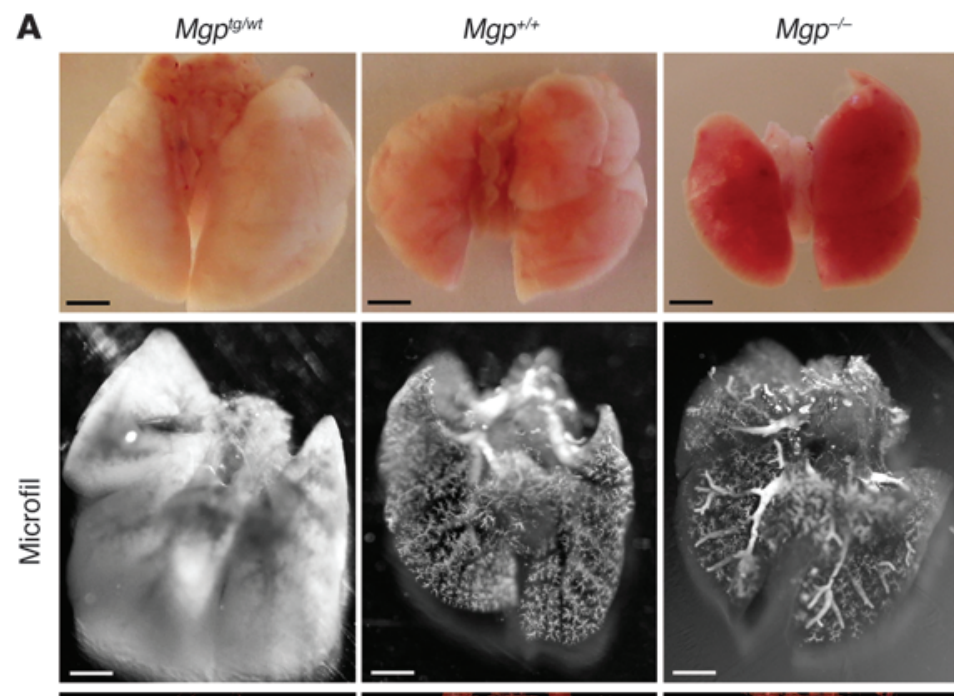

D

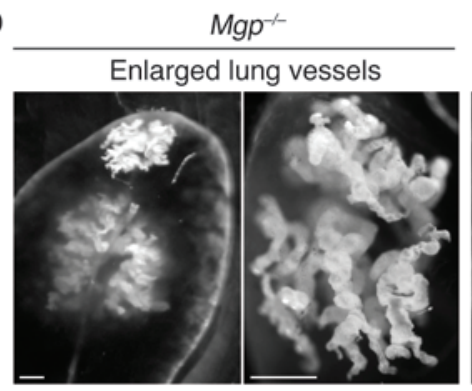

E

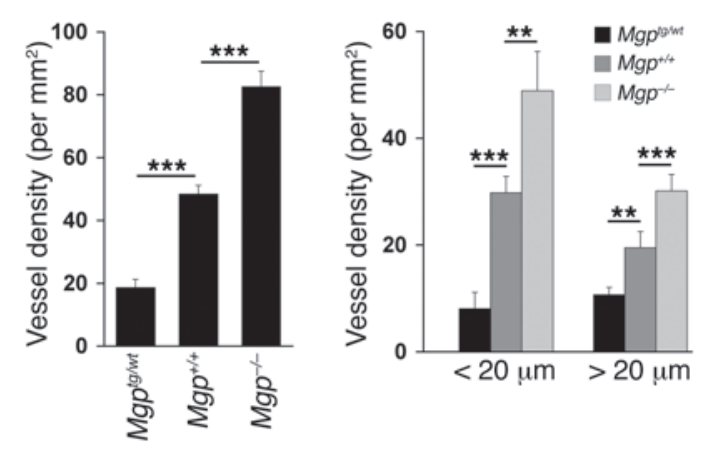

$\mathbf{F}$
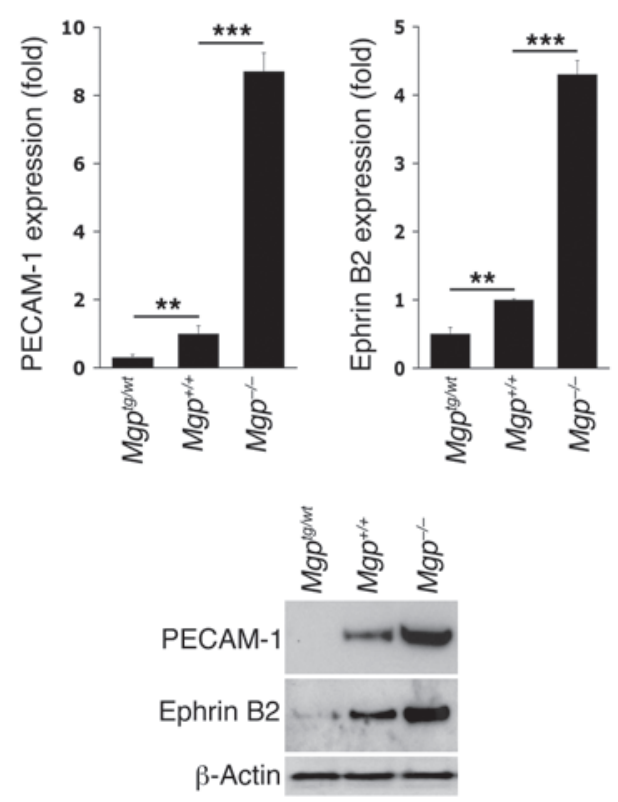


\section{Figure 1}

MGP levels influence pulmonary vascular development. (A) Photographs of lungs and micro $C T$ images of the pulmonary vasculature from $\mathrm{Mgp}^{\mathrm{tg} / \mathrm{wt}}, \mathrm{Mgp}^{+/+}$, and $\mathrm{Mgp}^{-/-}$mice. Data are from a single experiment but are representative of 3 repeat experiments. Stars represent visualized pulmonary veins. See Supplemental Videos 1-3 for full $3 \mathrm{D}$ reconstruction of the pulmonary vasculature. Microfil compound was used for organ perfusion in order to visualize the vasculature. (B) Expression of vWF in lung sections from $M g p^{t g / w t}, M g p^{+/+}$, and $\mathrm{Mgp}^{-/-}$mice, as determined by immunofluorescence $(n=3)$. Arrowheads indicate VWF-positive endothelium. (C) Presence of pulmonary arteriovenous shunts, as shown by UV-fluorescent microsphere passage. The microspheres bypassed the lungs in the $\mathrm{Mgp}^{-/-}$mice. BF, bright field. (D) Niduses of enlarged and tortuous blood vessels in $\mathrm{Mgp}^{-/}$lung (left panels). Direct arteriovenous (AV) connections on the surface of a $\mathrm{Mgp}^{-/-}$lung (right panel). (E) Vessel density in lungs from $M g p^{t g / w t}, M g p^{+/+}$, and $\mathrm{Mgp}^{-/-}$mice $(n=6)$. The left panel shows total vessel density, and the right panel shows vessel density of vessels with a caliber of less than $20 \mu \mathrm{m}$ and more than $20 \mu \mathrm{m}$. (F) Expression of PECAM-1 and Ephrin B2 in lung tissues from $\mathrm{Mgp}^{\mathrm{tg} / \mathrm{wt}}, \mathrm{Mgp}^{+/+}$, and $\mathrm{Mgp}^{-/}$mice, as determined by real-time PCR and immunoblotting. Asterisks indicate statistically significant differences compared with wild-type $\left(\mathrm{Mgp}^{+/+}\right) .{ }^{* *} P<0.01,{ }^{* * *} P<0.001$, Tukey's test. Scale bars: $2 \mathrm{~mm}$ (A, rows 1-3, and $\mathbf{C}) ; 500 \mu \mathrm{m}$ (A, row 4, and D, left and middle); $100 \mu \mathrm{m}$ (B and D, right).

(Figure 1A and Figure 2A, veins marked with stars). The presence of arteriovenous shunts was supported by vascular shunting of injected fluorescent microspheres (referred to herein as fluorescent microsphere passage) that would normally be retained in the tissue, which bypassed the $M g p^{-/-}$lungs and kidneys (Figure $1 \mathrm{C}$ and Figure 2C). Furthermore, niduses of enlarged and entangled vessels were observed in some of the $\mathrm{Mgp}^{-/-}$mice (Figure 1D and Figure 2D, left). Direct connections between an arterial segment and a venous segment were observed on the surface of the $M g p^{-/}$ lungs (Figure 1D, right), and both afferent and efferent arterioles were visualized in the $M g p^{-/-}$kidneys (Figure 2D, right), suggesting abnormal arteriovenous connections in the glomeruli. Less branching and no evidence of AVMs were seen in the vasculature of $M g p^{t g / w t}$ mice (Figure 1A and Figure 2A). In addition, the kidneys were heavier when normalized to total body weight in the $M g p^{-/}$mice and showed significantly more glomeruli per microscopic field than wild-type and $M g p^{t g / w t}$ mice (Supplemental Figure 1, A-D). Capillary density and diameter were examined by immunofluorescence with antibodies to the vWF. Both total capillary density and the number of capillaries with a diameter of more than $20 \mu \mathrm{m}$ increased when MGP decreased and were highest in the $M g p^{-1-}$ mice (Figure 1, B and E, and Figure 2, B and E). This suggests that AVMs are present (16). Expression of PECAM-1 and Ephrin B2, markers of mature and arterial ECs, respectively, (16), was significantly higher in lungs and kidneys from $\mathrm{Mgp}^{-/-}$mice compared with that of wild-type and $M g p^{t g / w t}$ mice, as determined by real-time PCR and immunoblotting (Figure 1F and Figure 2F). Together, the results suggested vascular dysregulation and the presence of AVMs in the $M g P^{-/-}$mice.

SMAD1/5/8 signaling is increased in type II epithelial cells. Since MGP acts as an inhibitor of BMP-2 and BMP-4 $(1,2)$, we determined whether levels of phosphorylated SMAD1/5/8 (pSMAD1/5/8) changed in MGP deficiency, using extracts and tissue from $\mathrm{Mgp}^{-/}$, $M g p^{t g / w t}$, and wild-type lungs. The results showed a strong increase in PSMAD1/5/8 when MGP was deficient, as determined by immunoblotting (Figure 3A) and immunofluorescence (Figure 3B).
pSMAD2 $/ 3$, mediating TGF- $\beta$ signaling, was also increased, consistent with previous data that BMP-4 induces TGF- $\beta$ signaling through ALK1 and ALK5 (14). Although pSMAD1/5/8 and pSMAD2/3 showed some colocalization with VE-cadherin (an EC marker), most of the pSMADs colocalized with surfactant protein B (SP-B) (a marker of type II epithelial cells; ref. 17 and Figure $3 \mathrm{~A}$ ), consistent with enhanced BMP signaling in type II epithelial cells in MGP deficiency.

Enhancement of BMP-induced gene expression in MGP-deficient type II epithelial lung cells. We previously identified a regulatory pathway induced by BMP-4 in ECs (Figure 4A for schematic outline) $(14,18,19)$. In this pathway, BMP-4 interacts with the ALK2 to stimulate expression of ALK1. ALK2 expression itself is also stimulated by enhanced BMP signaling. The induced ALK1 receptor is stimulated by BMP-9, which circulates in plasma (20), and induces expression of MGP and ALK5. MGP limits BMP-4 activity (2), and ALK5 is stimulated by TGF- $\beta 1$ to induce VEGF expression (14). We hypothesized that this pathway was activated in the type II epithelial lung cells and may contribute to AVMs by stimulating VEGF expression.

Our results showed that the expressions of ALK2, ALK1, ALK5, and VEGF were all significantly increased in $M g p^{-/-}$lungs and decreased in $M g p^{t g / w t}$ lungs, as determined by real-time PCR, immunoblotting, and immunofluorescence (Figure 4, B-D). However, the expression of BMP-4 in the lungs and BMP-9 in the liver remained unchanged (Figure 4B). As we expected, MGP expression increased in $M g p^{t g / w t}$ lungs but was absent in $M g p^{-/-}$lungs (Figure 4B).

Next, we determined where in the lungs the BMP-induced genes were expressed by colocalization. For these experiments, we used $M g \mathrm{P}^{-/-}$lungs and compared localization of ALK2, ALK1, ALK5, or VEGF with that of VE-cadherin and SP-B by immunofluorescence. Although the results revealed some colocalization of ALK2, ALK1, ALK5, and VEGF with VE-cadherin (Figure 4E), most of the colocalization was seen with SP-B (Figure 4E) in type II epithelial cells. Together, the results suggest that BMP-induced gene expression was enhanced in type II epithelial cells and that these cells were responsible for the increased VEGF in MGP deficiency.

VEGF is regulated by the BMP regulatory pathway in type II epithelial lung cells and affects EC proliferation. To explore BMP-mediated regulation of VEGF in lungs cells, we prepared primary lung cells from $M g p^{-1-}, M g p^{t g / w t}$, and wild-type 4-week-old mice. The initial cell preparations showed expression of Clara cell secretory protein (CCSP, Clara cell marker; ref. 21), aquaporin-5 (AQP-5, type I epithelial cell marker; ref. 22), SP-B, and PECAM-1 (Figure 5A). After the cells were cultured for 7 to 14 days, only cells expressing SP-B were detected (Figure 5A). These were used as a population representative of type II epithelial cells in subsequent experiments.

We first examined BMP activation in the isolated lung cells. The results revealed higher BMP and TGF- $\beta$ activation in $M g p^{-/-}$cells compared with that in $M g p^{t g} / w t$ and wild-type cells, as determined by immunoblotting (Figure 5B). pSMAD1/5/8 and pSMAD2/3 were also detected by immunofluorescence (Figure 5C) and were largely localized to the nuclei (Supplemental Figure 2 for $\mathrm{Mgp}^{-/-}$ cells), consistent with activated SMADs.

We then compared cell proliferation in ECs and type II epithelial cells from wild-type mice in response to conditioned media from the $M g p^{-/-}, M g p^{t g / w t}$, and wild-type lung cells. VEGF or antiVEGF antibodies were added to determine the importance of VEGF in the proliferative response. The results showed that conditioned media from the $M g p^{-/-}$cells stimulated proliferation of ECs but inhibited that of type II epithelial cells, as determined by 

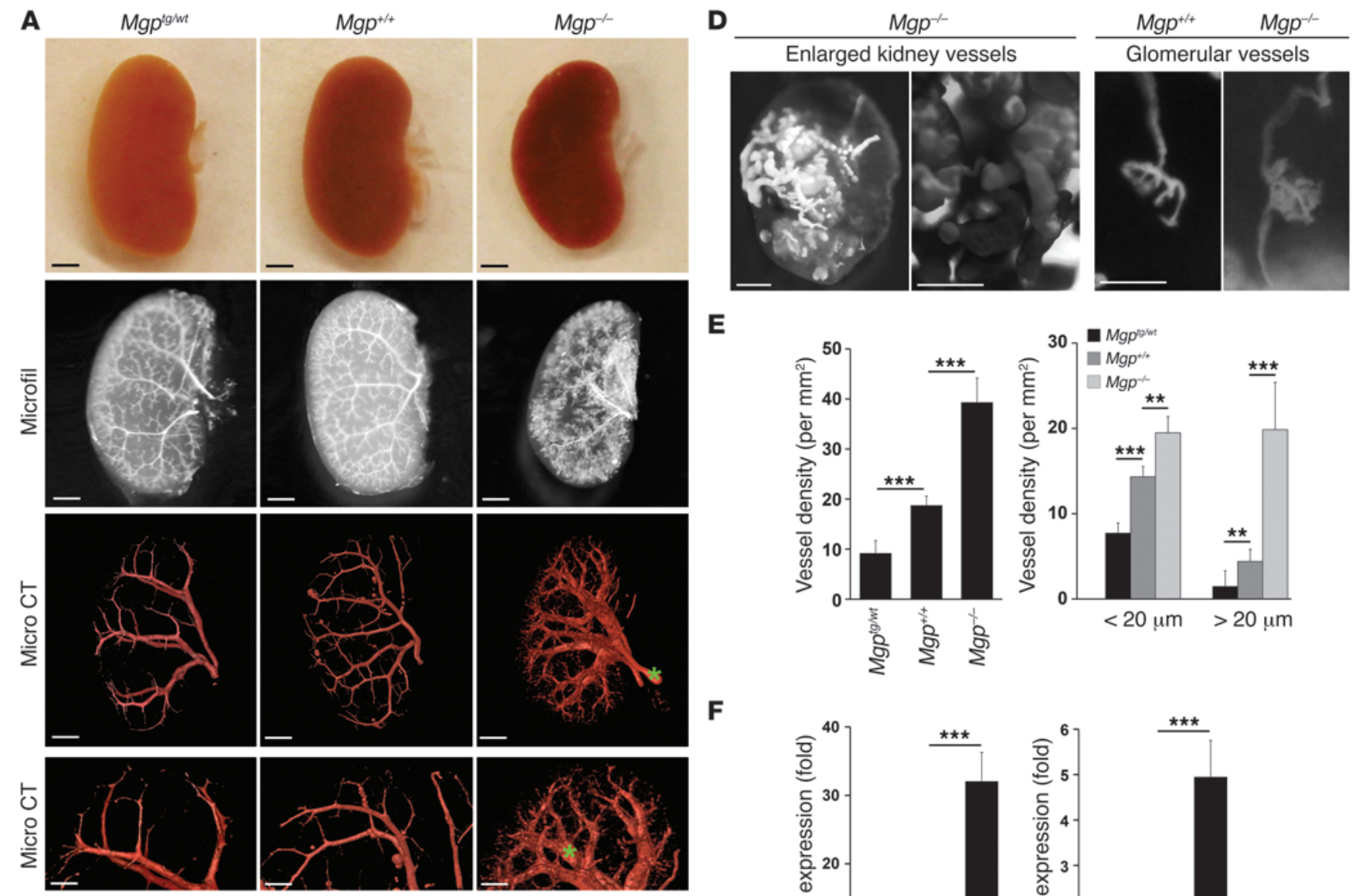

E
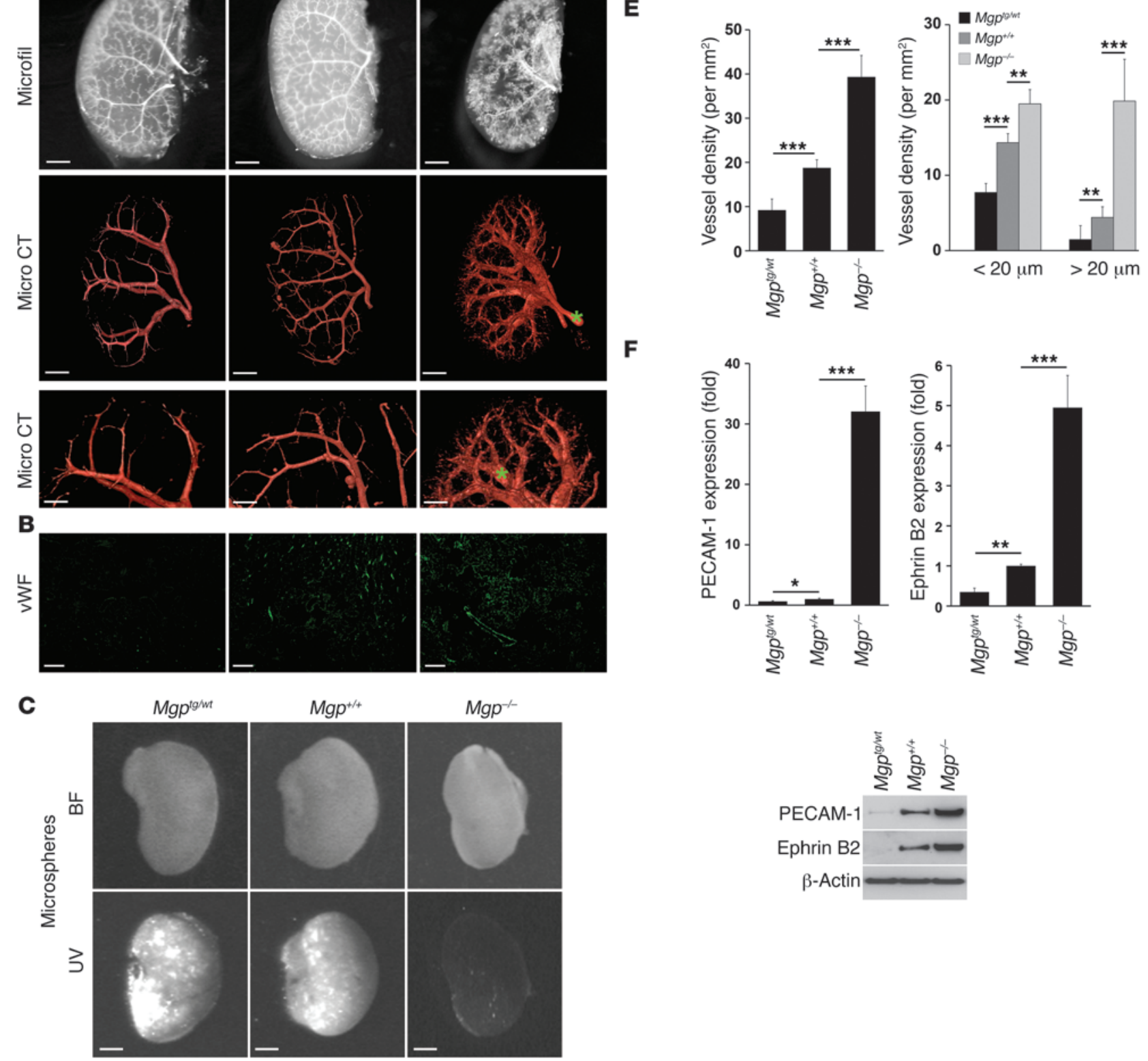


\section{Figure 2}

MGP levels influence renal vascular development. (A) Photographs of kidneys and micro CT images of the renal vasculature from $M g p^{t g / w t}$, $\mathrm{Mgp}^{+/+}$, and $\mathrm{Mgp}^{-/-}$mice. Data are from a single experiment but are representative of 3 repeat experiments. Stars represent visualized pulmonary veins. See Supplemental Videos 4-6 for full 3D reconstruction of the renal vasculature. (B) Expression of vWF in kidney sections from $\mathrm{Mgp}^{t g / \mathrm{wt}}, \mathrm{Mgp}^{+/+}$, and $\mathrm{Mgp}^{-/-}$mice, as determined by immunofluorescence $(n=3)$. (C) Presence of renal arteriovenous shunts, as shown by UV-fluorescent microsphere passage. The microspheres bypassed the kidneys in the $\mathrm{Mgp}^{-/-}$mice. (D) Nidus of enlarged and tortuous blood vessels in $\mathrm{Mgp}^{-/-}$kidney (left panels). Both afferent and efferent arterioles are apparent in $\mathrm{Mgp}^{-/}$kidneys but not in $\mathrm{Mgp}^{+/+}$ kidneys (right panels). (E) Vessel density in kidneys from $M g p^{t g / w t}$, $\mathrm{Mgp}^{+/+}$, and $\mathrm{Mgp}^{-/-}$mice $(n=6)$. The left panel shows total vessel density, and the right panel shows vessel density of vessels with a caliber of less than $20 \mu \mathrm{m}$ and more than $20 \mu \mathrm{m}$. (F) Expression of PECAM-1 and Ephrin B2 in kidney tissues from $\mathrm{Mgp}^{\text {tg/wt }}, \mathrm{Mgp}^{+/+}$, and $\mathrm{Mgp}^{-/}$mice, as determined by real-time PCR and immunoblotting. Asterisks indicate statistically significant differences compared with wild-type $\left(\mathrm{Mgp}^{+/+}\right)$ mice. ${ }^{*} P<0.05,{ }^{* *} P<0.01,{ }^{* *} P<0.001$, Tukey's test. Scale bars: $1 \mathrm{~mm}$ (A, rows 1-3, C, and D, left image); $200 \mu \mathrm{m}$ (A, row 4); $50 \mu \mathrm{m}$ (B and D, right center and right images); $500 \mu \mathrm{m}$ (D, left center image).

${ }^{3} \mathrm{H}$-thymidine incorporation (Figure 5D). Conversely, conditioned media from the $M g p^{t g / w t}$ cells inhibited proliferation of ECs but stimulated that of type II epithelial cells (Figure 5D). The proliferative response in ECs but not in type II epithelial cells was mediated by VEGF. Addition of anti-VEGF antibodies diminished stimulation of EC proliferation by conditioned media from all tested groups, whereas VEGF enhanced the proliferation (Figure 5D). Addition of control IgG had no effect. The results suggested that MGP interferes with the effect of BMP-4 on proliferation and that BMP-4 stimulation of EC proliferation is mediated by VEGF.

Because VEGF is induced by BMP-4, we also tested the importance of BMP-4 on cell proliferation in ECs and type II epithelial cells from wild-type mice. In this case, we used conditioned media from bovine aortic ECs (BAECs) overexpressing MGP, human aortic ECs (HAECs) depleted of MGP by siRNA, or control-transfected cells. BMP-4 (40 ng/ml) or anti-BMP-4 antibodies $(300 \mathrm{ng} / \mathrm{ml})$ were added. Again, the results showed that MGP depletion stimulated proliferation of ECs but inhibited that of type II epithelial cells (Figure 5E), whereas excess MGP inhibited proliferation of ECs but stimulated that of type II epithelial cells (Figure 5E). Addition of BMP-4 stimulated EC proliferation by conditioned media from all tested groups but inhibited that of the lung cells (Figure 5E). However, anti-BMP-4 antibodies had the reverse effect. Together, the results suggest that lack of MGP inhibits proliferation of type II epithelial cells but stimulates proliferation of ECs by enhancing VEGF expression. The inhibited growth of type II epithelial cells is also supported by a paucity of terminal airways in the $\mathrm{Mgp}^{-/-}$mice (Supplemental Figure 3).

We next determined whether the BMP pathway regulated VEGF expression in type II epithelial cells using cells from $M g p^{-/-}, M g p^{t g / w t}$, and wild-type mice, treating them with BMP-4, BMP-9, and TGF- $\beta 1$. These experiments are described in the supplemental materials (Supplemental Figure 4). The results showed that BMP-4 induced VEGF in type II epithelial cells through ALK2, ALK1, and ALK5, findings that were similar to the previous results in ECs $(14,18)$. This pathway was highly activated in $\mathrm{MgP}^{-/-}$cells, suggesting that the increased BMP activity is responsible for the VEGF induction. We further verified the importance of the BMP pathway and SMAD1 for VEGF induction using siRNA (Supplemental Figure 4).

$B M P-7$ regulates $V E G F$ through the $B M P$ regulatory pathway in renal mesangial cells. Both BMP-4 and BMP-7 have been shown to play important roles in renal development (23). Although dramatic changes were observed when MGP levels were altered, it is not clear which BMP actually regulates VEGF in renal vascular development. We first determined the expression of BMP-4, BMP-7, ALK2, ALK1, ALK5, and VEGF in the kidneys from $M g p^{-/-}, M g p^{t g / w t}$, and wild-type mice. Expression of ALK2, ALK1, ALK5, and VEGF, but not BMP-4 and BMP-7, was significantly increased in the $\mathrm{MgP}^{-/-}$ mice and decreased in the $M g p^{t g / w t}$ mice, as determined by real-time PCR and immunoblotting (Figure 6A, compare with lung expression in Figure 4, B and C). Furthermore, renal pSMAD1/5/8 and pSMAD2/3 levels increased in the $M g p^{-/-}$mice but decreased in the $M g p^{t g / w t}$ mice, as determined by immunoblotting (Figure 6C). Both PSMAD 1 and PSMAD2/3 colocalized with $\alpha$-smooth muscle actin, which is used as a marker of mesangial cells in the kidneys (Supplemental Figure 5).

VEGF is expressed by mesangial cells and podocytes and acts on these cells as well as on ECs (24). To determine whether BMP-4 or BMP-7 more efficiently regulates VEGF expression in these cell types, we treated mesangial cells and podocytes with BMP-4 or BMP-7 $(0-80 \mathrm{ng} / \mathrm{ml})$ for 24 hours. The results showed that BMP7 was more efficient in inducing VEGF in mesangial cells than BMP-4 (Figure 6D), whereas no induction of VEGF was detected in podocytes (data not shown).

Next, we determined whether BMP-7 activated the BMP regulatory pathway and induced MGP and VEGF in mesangial cells using siRNA techniques. The mesangial cells were transfected with scrambled control siRNA or siRNA for MGP, ALK2, ALK1, ALK5, SMAD1, or SMAD2 and then treated with BMP-7 (0-80 ng/ml), starting on the day after transfection. Expression of MGP, ALK2, ALK1, ALK5, and secreted VEGF was determined by real-time PCR and/or immunoblotting. The results showed that MGP induction was abolished by depletion of ALK2, ALK1, and SMAD1 (Figure 6E), supporting the hypothesis that ALK2 and ALK1 mediated induction of MGP through SMAD1. As expected, depletion of MGP enhanced BMP-7-induced expression of ALK2, ALK1, ALK5, and VEGF (Figure 6F). Furthermore, depletion of ALK2 and SMAD1 abolished induction of ALK1, ALK5, and VEGF; depletion of ALK1 abolished induction of ALK5 and VEGF; and depletion of ALK5 abolished induction of VEGF (Figure 6F). The results suggested that BMP-7 activated the same regulatory system in the mesangial cells that BMP-4 activated in the type II epithelial cells. We also found that MGP binds and inhibits BMP-7 and BMP-4 in a similar manner in experiments using a luciferase reporter gene, coimmunoprecipitation, and cross-linking (Supplemental Figure 6).

Alk1-deficient mice have decreased expression of MGP in lungs and kidneys. Heterozygous ALK1-deficient $\left(A l k 1^{+-}\right)$mice are a mouse model of HHT that develop AVMs (25). Because ALK1 signaling enhances MGP expression $(14,18)$, we hypothesized that the Alk $1^{+/-}$mice would have decreased MGP levels. We collected lungs and kidneys from $A l k 1^{+/-}$mice, aged 20 weeks, and determined MGP expression. Both lungs and kidneys showed decreased expression of MGP, as determined by real-time PCR, compared with that of wild-type controls (Supplemental Figure 7A). Tissue levels of MGP were also decreased, as determined by immunofluorescence 


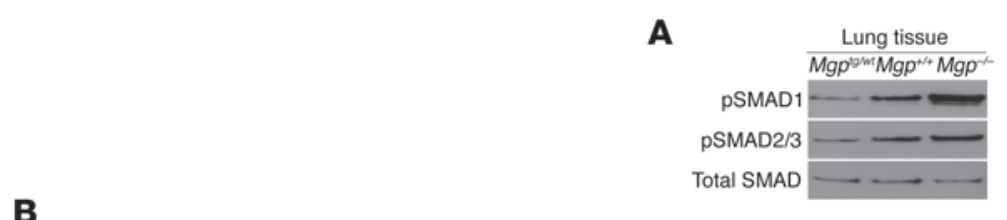

B
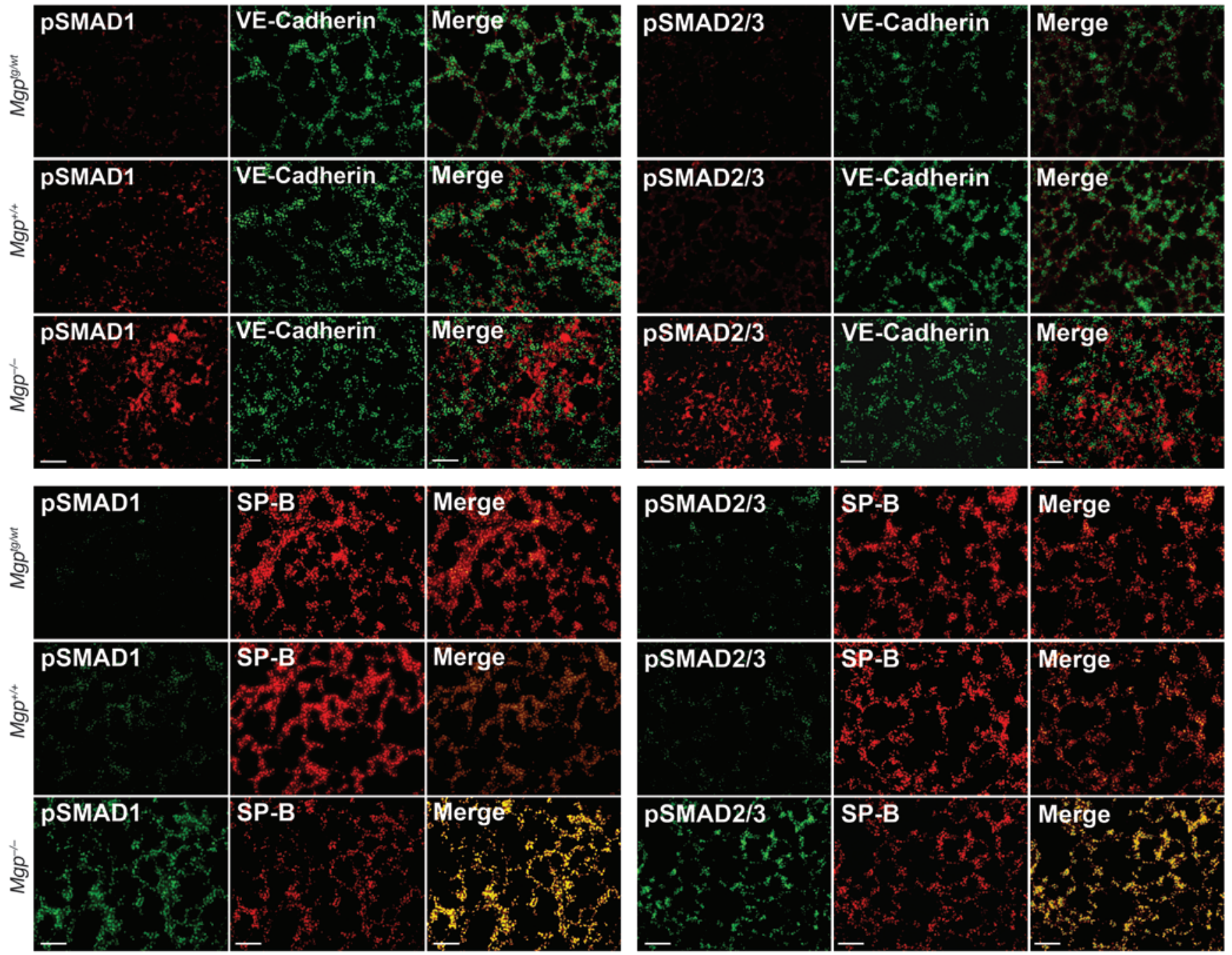

Figure 3

BMP activity increases as MGP levels decrease in lung tissue. (A) pSMAD1 and pSMAD2/3 in lung tissue from $\mathrm{Mgp}^{\text {tg/wt }}, \mathrm{Mgp}^{+/+}$, and $\mathrm{Mgp}^{-/-}$mice, as determined by immunoblotting, compared with total SMAD. (B) Colocalization of pSMAD1 and pSMAD2/3 with VE-cadherin (EC marker) and SP-B (marker for type Il epithelial lung cells) in lung sections from $\mathrm{Mgptg}^{\mathrm{t} / \mathrm{wt}}, \mathrm{Mgp}^{+/+}$, and $\mathrm{Mgp}^{-/-}$mice. Scale bars: $10 \mu \mathrm{m}$ (B).

(Supplemental Figure 7B). Thus, low MGP levels are a common

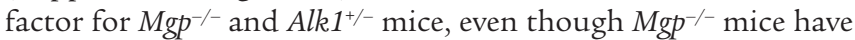
increased ALK1 levels and Alk1+- mice have reduced ALK1 levels. This suggests that low MGP levels may contribute to the formation of AVMs in ALK1 deficiency.

\section{Discussion}

Multifocal peripheral pulmonary artery stenoses in the Keutel syndrome (8) and inhibited pulmonary vascular development in Mgptransgenic mice (6) point to a pivotal role of MGP in the pulmonary vasculature. In this study, we demonstrated that MGP deficiency is indeed a major determinant of both pulmonary and renal vascularization, including the formation of a normal capillary networks, and the number of glomeruli. The importance of MGP in preventing AVMs has not been reported previously to our knowledge and suggests that BMP inhibition could be a new strategy in treating AVMs. Vascular abnormalities such as AVMs are clinically significant problems that may be due to genetic disorders such as HHT (10) or emerge as a secondary effect of, for example, liver failure (26). AVMs lack the normal capillary network that progressively dampens the blood pressure and optimizes delivery of nutrient and oxygen. Instead, arteries and veins are connected by thin-walled, large-caliber shunts with high propensity for bleeding. Bleeding from AVMs may have devastating clinical effects, including life-threatening pulmonary or gastrointestinal hemorrhages and hemorrhagic strokes $(10,25)$. Our studies showed that low MGP levels were common for both 


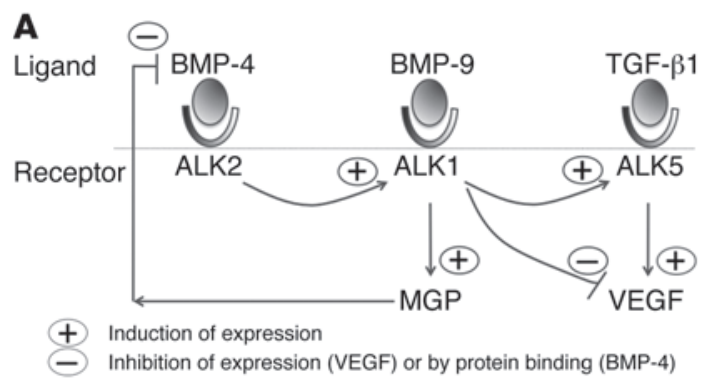

B

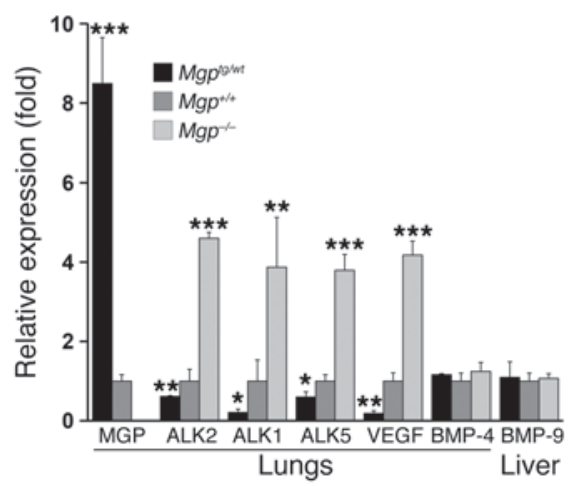

C

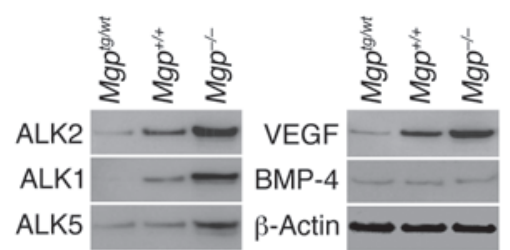

E

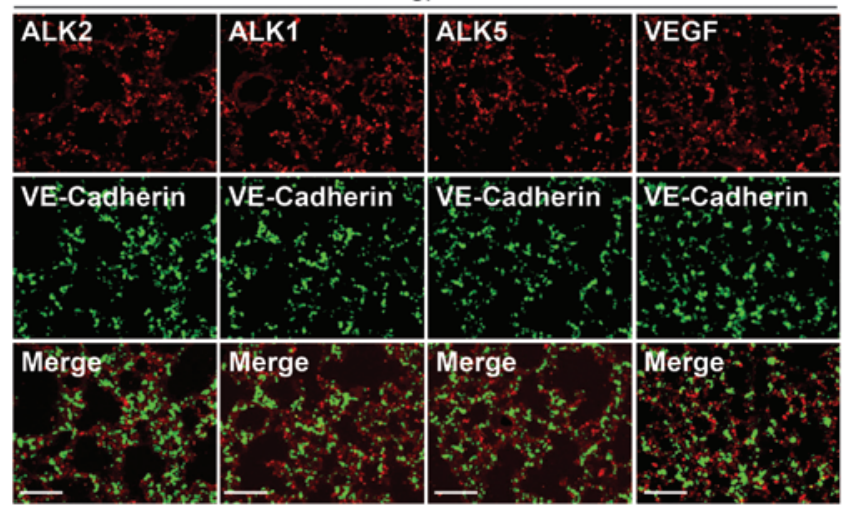

D

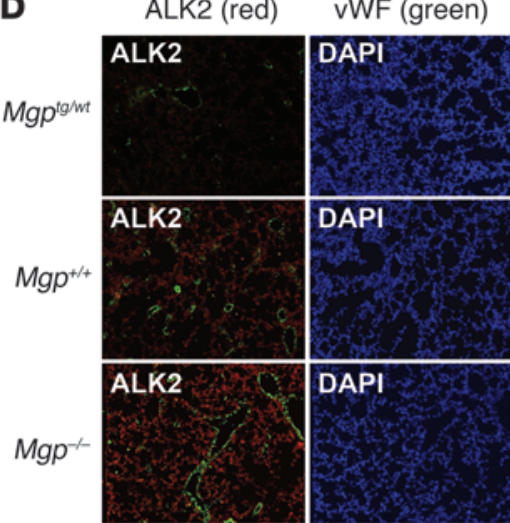

ALK5 (red)

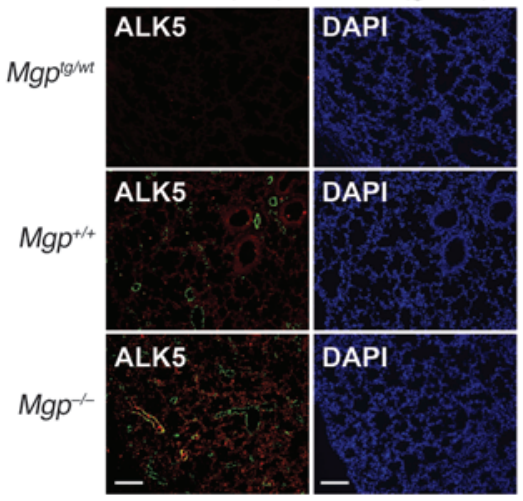

ALK1 (red)

VWF (green)
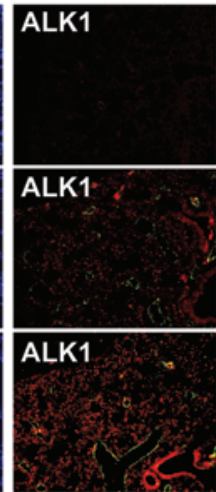

VEGF (red)
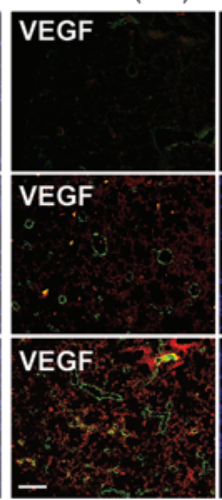

DAPI

vWF (green)

DAPI

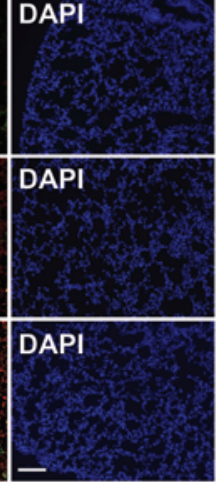

DAPI

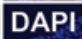

DAPI

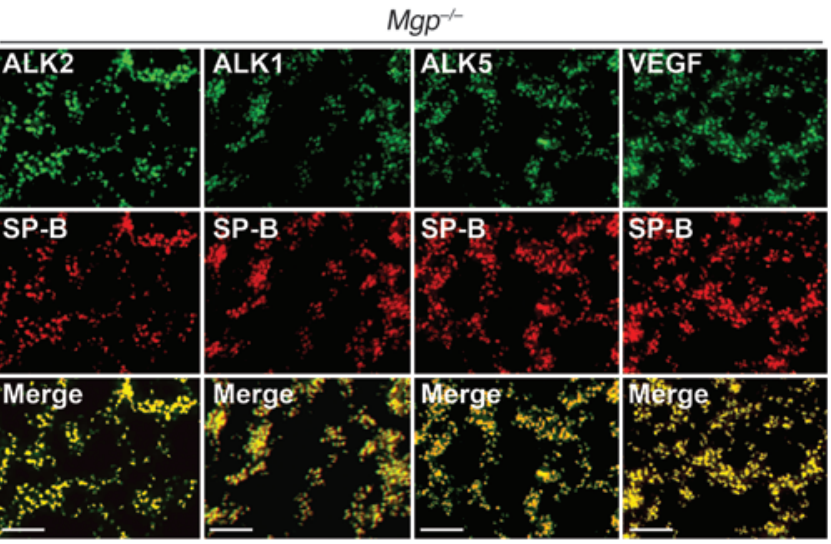

Figure 4

BMP-regulated gene expression is increased in MGP-deficient lungs. (A) Schematic outline of the BMP-4 induced pathway in ECs. (B and C) Expression of MGP, ALK2, ALK1, ALK5, VEGF, and BMP-4 in lung tissue and BMP-9 in liver from Mgptg/wt, $\mathrm{Mgp}^{+/+}$, and $\mathrm{Mgp}^{-/-}$mice, as determined by real-time PCR and immunoblotting. Asterisks indicate statistically significant differences compared with wild-type $\left(M g p^{+/+}\right)$mice. ${ }^{*} P<0.05$, ${ }^{\star \star} P<0.01,{ }^{* * *} P<0.001$, Tukey's test. (D) Costaining of ALK2, ALK1, ALK5, and VEGF with vWF in lung sections from Mgp ${ }^{t g / w t}, M g p^{+/+}$, and $\mathrm{Mgp}^{-/-}$mice. (E) Costaining of ALK2, ALK1, ALK5, and VEGF with VE-Cadherin (left) or SP-B (right) in lung sections from Mgp ${ }^{-/-}$mice. Scale bars: $100 \mu \mathrm{m}(\mathbf{D}) ; 10 \mu \mathrm{m}(\mathrm{E})$.

$M g p^{-/-}$and Alk1+/- mice, even though $\mathrm{Mgp}^{-/-}$mice had increased ALK1 levels (Figure 4B) and $A l k 1^{+/-}$mice had reduced ALK1 levels (Figure 5 in ref. 14). This suggests that a reduction of MGP, whether congenital or acquired, may contribute to the development of AVMs.

AVMs related to human HHT are caused by loss of ALK1 signaling $(10,11)$. However, both serum levels of VEGF and expression of VEGF in nasal mucosa are increased in HHT patients
(13), consistent with the findings in the $A l k 1^{+/-}$mice. This suggests that both the $A l k 1^{+/-}$mice and the $M g p^{-/-}$mice are relevant to human HHT. The difference in ALK1 expression between $\mathrm{Alk1}^{+/-}$and $\mathrm{MgP}^{-/-}$mice is likely due to the specifics of the regulatory connections among BMP-4, ALK1, and MGP (Figure 4A). In $A l k 1^{+/-}$mice, partial gene deletion results in low ALK1 levels, which causes a dysregulated increase of VEGF through an 
A

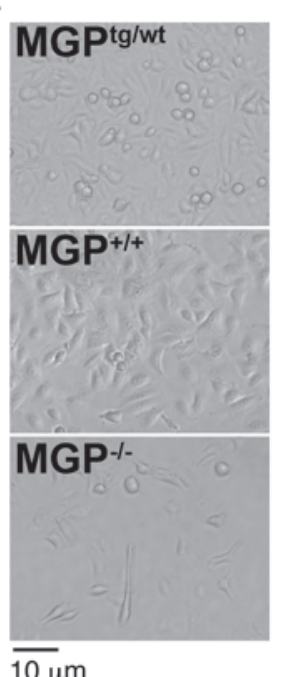

$\overline{10 \mu \mathrm{m}}$
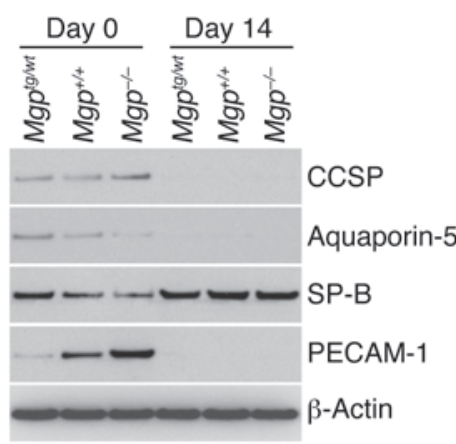

B

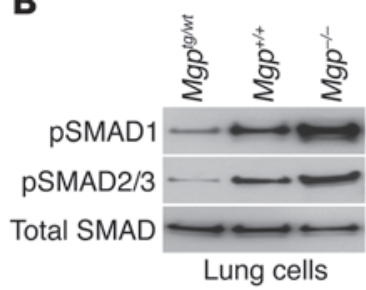

C

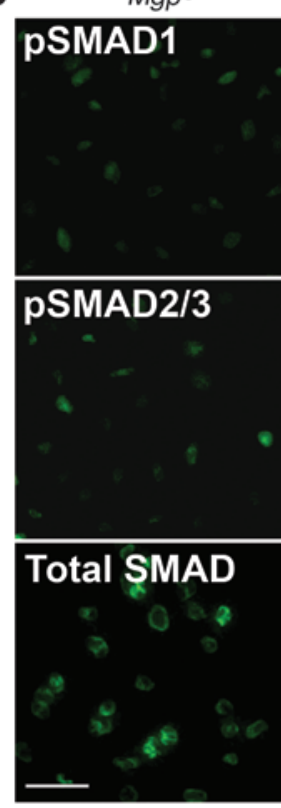

$\mathrm{Mgp}^{+/+}$
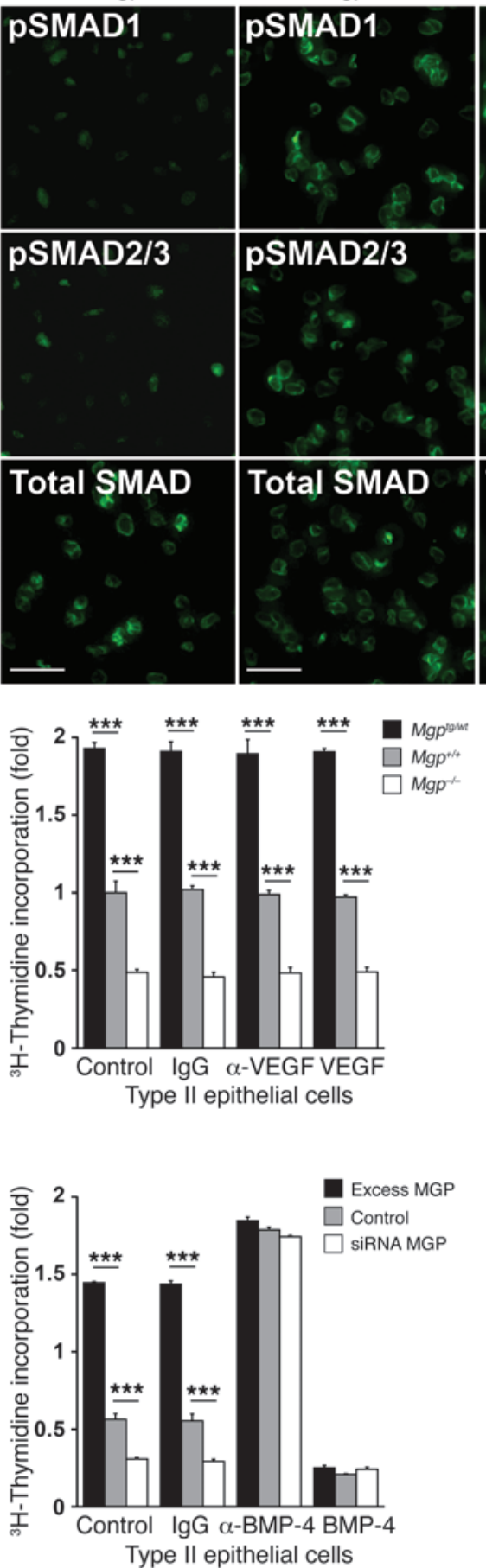

Figure 5

SMAD activation and proliferation in ECs versus that in type II epithelial lung cells. (A) Lung cells that were cultured for 14 days (shown by phase-contrast microscopy, left) retained expression of SP-B (type II epithelial cell marker), as shown by immunoblotting (right), but not of CCSP (Clara cell marker), AQP-5 (type I epithelial cell marker), or PECAM-1 (EC marker). (B and C) pSMAD1 and pSMAD2/3 in SP-B-expressing type II epithelial cells from $\mathrm{Mgp}^{\mathrm{tg} / \mathrm{wt}}, \mathrm{Mgp}^{+/+}$and $\mathrm{Mgp}^{-/-}$mice, as determined by $(\mathbf{B})$ immunoblotting and (C) immunofluorescence, compared with total SMAD. (D) Cell proliferation in HAECs (left panel) and type Il epithelial cells from wild-type mice (right panel) in response to conditioned media from type II epithelial cells isolated from $\mathrm{Mgp}^{t g / \mathrm{wt}}, \mathrm{Mgp}^{+/+}$, and $\mathrm{Mgp}^{-/-}$mice. Cells were treated with control vehicle, anti-VEGF antibodies or nonspecific IgG (300 ng/ml), or VEGF (10 ng/ml). Asterisks indicate statistically significant differences. ${ }^{\star \star *} P<0.001$, Tukey's test. (E) Cell proliferation in HAECs (left panel) and type II epithelial cells from wild-type mice (right panel) in response to conditioned media from BAECs transfected with N-FLAG-hMGP expression vector (excess MGP), empty expression vector (control), or HAECs depleted of MGP (siRNA MGP). Cells were treated with control vehicle, anti-BMP-4 antibodies or nonspecific lgG (300 ng/ml), or BMP-4 (40 ng/ml). Asterisks indicate statistically significant differences. ${ }^{* *} P<0.001$, Tukey's test. Scale bars: $10 \mu \mathrm{m}$ (C). 


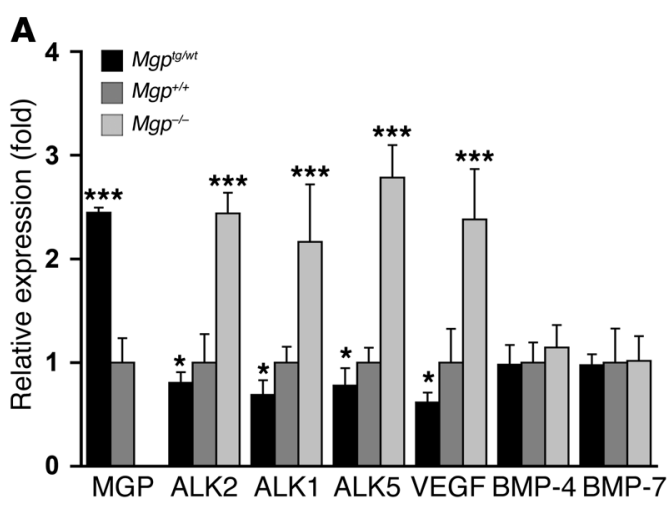

D

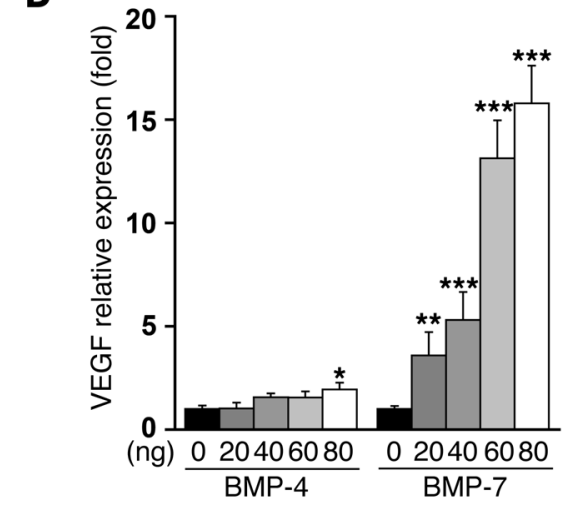

E

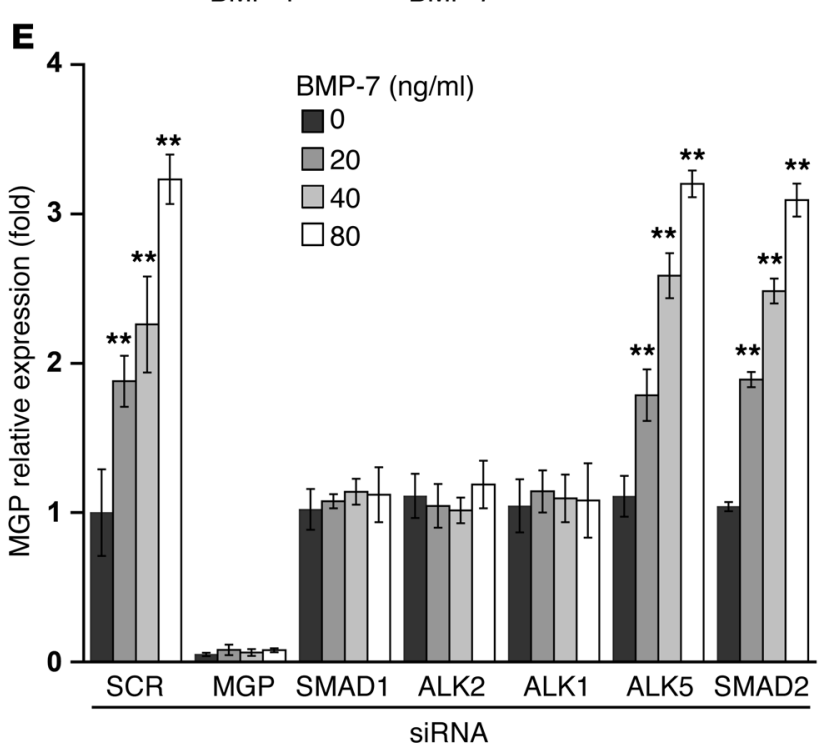

B

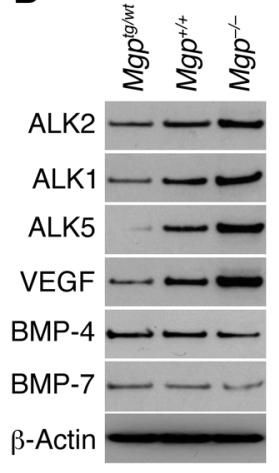

C

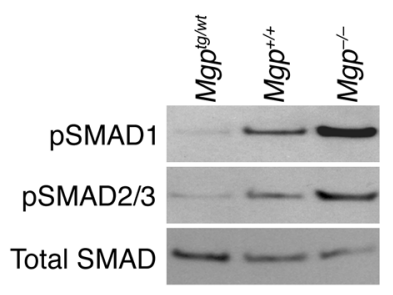

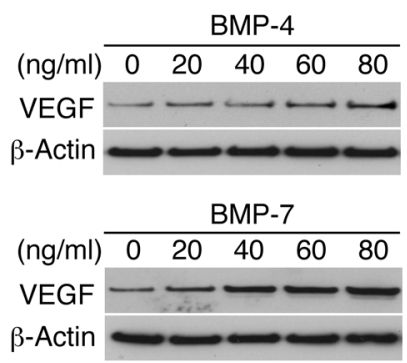

$\mathbf{F}$

F
BMP-7 (ng/ml) 0

\section{Figure 6}

BMP-regulated gene expression is increased in MGP-deficient kidneys. (A and B) Expression of MGP, ALK2, ALK1, ALK5, VEGF, BMP-4, and BMP-7 in kidneys from Mgptg/wt, $\mathrm{Mgp}^{+/+}$, and $\mathrm{Mgp}^{-/-}$mice, as determined by (A) real-time PCR and (B) immunoblotting. (C) pSMAD1 and pSMAD2/3 and total SMAD in kidneys from $\mathrm{Mgp}^{t g / w t}, \mathrm{Mgp}^{+/+}$, and $\mathrm{Mgp}^{-/-}$mice, as determined by immunoblotting, compared with total SMAD. (D) VEGF expression in renal mesangial cells after treatment with BMP-4 or BMP-7 (0-80 ng/ml), as determined by real-time PCR and immunoblotting. ( $E$ and $\mathbf{F}$ ) Expression of MGP after transfection of scrambled siRNA or siRNA to MGP, SMAD1, ALK2, ALK1, ALK5, and SMAD2 in mesangial cells and treatment with BMP-7 $(0-80 \mathrm{ng} / \mathrm{ml})$, as determined by $(\mathbf{E})$ real-time PCR and $(\mathbf{F})$ immunoblotting. Treatment was started 24 hours after transfection and lasted 24 hours. Asterisks indicate statistically significant differences compared with control (no BMP-7). SCR, scrambled control. ${ }^{*} P<0.05,{ }^{* *} P<0.01,{ }^{* *} P<0.001$, Tukey's test. 
unknown mechanism (14) but suppresses MGP. In $M g p^{-/-}$mice, the absence of MGP allows BMP-4 to boost ALK1 expression, which will ultimately promote VEGF expression through an induction of ALK5/TGF- $\beta 1$ signaling (14).

A reduction of functional MGP may also occur during warfarin treatment, which interferes with the vitamin $\mathrm{K}$-dependent gamma-carboxylation of glutamate residues. We have previously shown that gamma-carboxylated glutamates (Gla residues) are required for the binding of MGP to BMP-4 (2). Noncarboxylated MGP has been reported in the vasculature after warfarin treatment and may increase the risk for vascular and valvular calcification (27). However, it is not known whether warfarin promotes AVMs or increases local expression of VEGF. Such an effect would likely depend on the warfarin dose and patient sensitivity.

Renal AVMs have not been reported in Keutel syndrome as far as we know. Indeed, renal AVMs are rare (28) and have only been reported as case reports in patients with HHT (29), possibly because the kidneys are not routinely investigated. However, it has been shown that patients with HHT have an increased prevalence of hematuria (47\% versus $12 \%$ in control subjects; ref. 30 ), suggesting that renal vascular malformations may be more common than reported. We found a prominent increase in the number of glomeruli in the MGP-deficient kidneys, suggesting that the modulation of BMP activity is a mechanism for determination of the number of glomeruli. However, the functional importance of this is unclear, because the $\mathrm{MgP}^{-/-}$mice did not show increases in serum phosphate levels, a sign of renal insufficiency, in previous studies (15).

In our regulatory pathway, BMP-4 regulates VEGF and MGP through induction of ALK1 (Figure 4A and refs. 14, 18, 19). BMP-9, which circulates in plasma, subsequently activates ALK1 and enhances VEGF expression through an ALK5/TGF- $\beta$-mediated step. Without this step, VEGF expression is suppressed by ALK1/BMP-9. Our results show that type II pulmonary epithelial cells activate VEGF expression through the same pathway and provide most of the VEGF in the lungs. EC proliferation increases in response to BMP-4 activity, which is mediated by VEGF. However, type II epithelial cell proliferation decreases and is unaffected by VEGF. Instead, it is stimulated by BMP-4 inhibition resulting from high levels of MGP or anti-BMP-4 antibodies. This is consistent with the alveolar increase in the $M g p^{t g / w t}$ mice suggested by the examination of the terminal airways (Supplemental Figure 3). Overall, the findings suggest that an imbalance in BMP activity will affect the coordination between ECs and lung cells, which is an essential factor in tissue organization. This supports the concept that the same stimulus generates different responses in different cell types, a concept that could be applied to any pair of cells to optimize coordination of growth. Furthermore, it may be a mechanism for mutual regulation by 2 neighboring cells.

Renal mesangial cells also regulate VEGF expression in response to BMP stimulation, predominantly by BMP-7 in our experiments. Although BMP-7, like BMP-4, binds and inhibits MGP, it is not clear if the renal AVMs in MGP deficiency are the result of enhanced BMP-7 activity alone or a combination of BMP-4 and BMP-7 activity. Both BMPs are important for renal development (23), and their relative affinity for MGP has not been determined. VEGF regulation in podocytes does not appear to respond to BMP-4 or BMP-7 in our experiments, even though podocytes play an important role in VEGF regulation in kidneys (24).
It is striking that AVMs coexist with massive arterial calcification in the $\mathrm{Mgp}^{-/-}$mice $(4,5)$, demonstrating differences between vascular beds in response to MGP deficiency. The calcification has been reported to affect all elastic and muscular arteries but not arterioles, capillaries, or veins (4). We were unable to detect calcification in the pulmonary and the intrarenal circulation, which supports the previous observations. Understanding the connection between arterial calcification and AVMs will require further studies, but we speculate that abnormalities in endothelial function play a key role. For example, in hyperlipidemic MGP-deficient mice, the endothelium does not show the expected expression of endothelial adhesion proteins (31). Furthermore, excessive ALK2 activity was recently linked to abnormal EC differentiation (32) and may also play a role in the MGP-deficient mice.

Our research shows that a causal relationship between $M g p$ gene deletion and AVMs in lungs and kidneys and possibly other organs exists. This suggests that it is possible that abnormalities in MGP function contribute to the triggering of AVMs in HHT. In addition, $M g p$ gene deletion is a striking example of the same gene defect causing different pathologies in different vascular beds.

\section{Methods}

Animals. Mgptg $p^{t / w t}$ mice on a C57BL/6J background were generated as previously described (6), and $M g p^{+/-}$mice on a C57BL/6J background (4) were obtained from Cecilia Giachelli (University of Washington, Seattle, Washington, USA, with the permission of Gerard Karsenty (Columbia University, New York, New York, USA). Alk1 $1^{+/-}$mice on a C57BL/6J background were obtained from The Jackson Laboratory. Genotypes were confirmed by PCR $(5,6)$, and experiments were performed with generation F4-F6. Littermates were used as wild-type controls. All mice were fed a standard chow diet (Diet 8604, Harlan Teklad Laboratory). All mice were used for experiments at 4 weeks of age, except the $A l k 1^{+/-}$mice, which were used at 20 weeks of age. The investigation conformed to the Guide for the Care and Use of Laboratory Animals published by the US National Institutes of Health (NIH Publications No. 85-23, revised 1996) and had been reviewed and approved by the Institutional Review Board of the UCLA.

Micro CT imaging. Micro CT was performed by Numira Biosciences, and the specimens were prepared as per their instructions. The mice were sacrificed and immediately perfused through the right ventricle (for lungs) or the left ventricle (for kidneys) with PBS until the perfusate that drained through an atrial vent was essentially free of blood. The curing agent was added to the MICROFIL compound (Flow Tech Inc.). When the perfusion was complete, the MICROFIL compound was infused through the ventricular cannula using a syringe. The infusion was continued until the MICROFIL compound flowed freely from the atrial vent. The ventricular and atrial cannulas were then clamped, and the mice were placed at $4^{\circ} \mathrm{C}$ overnight. After adequate polymerization of the MICROFIL compound, the organs were harvested, rinsed with icecold PBS, and incubated in 10\% neutral-buffered formalin for 24 hours before undergoing micro CT.

All samples were scanned on a high-resolution, volumetric micro CT scanner ( $\mu$ CT 40, ScanCo Medical) at Numira Biosciences. The image data were acquired with the following parameters: $10-\mu \mathrm{m}$ isotropic voxel resolution; 200-ms exposure time; 2,000 views; and 5 frames per view. The micro CT generated DICOM files were used to analyze the samples and to create volume renderings of the regions of interest. The raw data files can be viewed using Microview (GE Healthcare) and AltaViewer (Numira Software). Additionally, images of the sample were generated using SCIRun (Scientific Computing and Imaging Institute, University of Utah; http://www.sci.utah.edu/cibc/software/106-scirun.html). 
Vascular casting. Vascular casting of the pulmonary and renal vasculature were both performed by perfusing the MICROFIL compound as described for micro CT. However, after the MICROFIL compound had cured over night, the tissue was subjected to a clearing sequence with different concentrations of alcohol ranging from $25 \%$ to $100 \%$ over 7 days. In a final step, the tissue was cleared by methyl salicylate, and the tissue was photographed.

Vascular shunting. Fifteen- $\mu \mathrm{m}$ fluorescent microspheres (Invitrogen) were injected into the right or left ventricle immediately after sacrificing the mice, and tissues were examined and photographed under UV light.

Tissue culture and siRNA transfections. HAECs were cultured as previously described $(18,33)$. Primary lung cells were prepared from mice lungs, as previously described (6), and cultured in DMEM supplemented with $10 \%$ FBS. For treatment of primary pulmonary cells, BMP-9 $(10 \mathrm{ng} / \mathrm{ml})$, TGF- $\beta 1$ $(1 \mathrm{ng} / \mathrm{ml})$, and soluble ALK1 fragment $(300 \mathrm{ng} / \mathrm{ml}$ ) (all from R\&D Systems) were added as indicated in the legend for Supplemental Figure 4. Stable mouse mesangial (MES-13) cells were obtained from ATCC and were cultured as per their recommendations. Podocytes were prepared and cultured as previously described (34).

Transient transfections of primary lung cells or HAECs with siRNA (Silencer Predesigned siRNA, Ambion) were performed with Lipofectamine 2000 (Invitrogen) using $60 \mathrm{nM}$ siRNA. The amount of siRNA was optimized as per the manufacturer's instructions. Three separate siRNAs and scrambled siRNA with the same nucleotide content were tested. When compared with unrelated control siRNA and scrambled siRNA, the specific siRNAs resulted in an 80\%-95\% decrease in mRNA and protein levels, as determined by real-time PCR and immunoblotting, respectively. The siRNA that provided the most efficient inhibition (90\%-95\%) was used for all the experiments. Silencer Predesigned siRNAs were obtained for ALK2, ALK1, ALK5, SMAD1, SMAD2, and MGP. BAECs and mesangial cells were transiently transfected with an expression construct for N-terminally FLAG-tagged human MGP (pN-FLAG-hMGP) (18) or empty control plasmid using FuGene 6 (Roche Applied Science) as previously described (18). Conditioned media for the proliferation experiments was prepared by allowing growth medium (DMEM with 15\% FBS) to incubate for 24 hours with the transfected cells. Incubation was initiated 3 hours after transfection and after removal of FuGene 6.

RNA analysis. Real-time PCR analysis was performed as previously described (35). GAPDH was used as a control gene (35). Primers and probes for mouse BMP-4, BMP-7, BMP-9, MGP, ALK1, ALK2, ALK5, VEGF, SMAD1, SMAD2, PECAM-1, and Ephrin B2 were obtained from Applied Biosystems as part of the TaqMan Gene Expression Assays.

Immunoblotting. Immunoblotting was performed as previously described (36). Equal amounts of cellular protein or culture medium were used. For optimal detection of VEGF in culture media, VEGF was first immunoprecipitated with anti-VEGF antibodies (Santa Cruz Biotechnology Inc.) as previously described (35). Results were then analyzed by immunoblotting using specific antibodies to VEGF $(200 \mathrm{ng} / \mathrm{ml}$; R\&D Systems). Blots were incubated with specific antibodies to pSMAD1/5/8 and pSMAD2/3 (both $400 \mathrm{ng} / \mathrm{ml}$; Cell Signaling Technology); total SMAD, BMP-4, ALK1, ALK2, ALK5, PECAM-1, Ephrin B2, and VE-cadherin (all $400 \mathrm{ng} / \mathrm{ml}$; Santa Cruz Biotechnology Inc.); VEGF and BMP-7 (both $200 \mathrm{ng} / \mathrm{ml}$; R\&D Systems); SP-B (4 $\mu \mathrm{g} / \mathrm{ml}$; Upstate-Millipore); FLAG $(2.5 \mu \mathrm{g} / \mathrm{ml}$; Sigma-Aldrich); AQP-5 (5 $\mu \mathrm{g} / \mathrm{ml}$; Calbiochem); or CCSP (1:2,000 dilution; Upstate-Millipore). $\beta$-Actin (1:5,000 dilution; SigmaAldrich) was used as loading control.

Immunofluorescence. Tissue sections were fixed in $4 \%$ paraformaldehyde and processed as previously described (37). Immunofluorescence was performed in detail as previously described (38). We used specific antibodies for pSMAD1/5/8 (Santa Cruz Biotechnology Inc.); pSMAD2/3 (Cell Sig- naling Technology); total SMAD, ALK1, ALK2, ALK5, VE-cadherin, and VEGF (all from Santa Cruz Biotechnology Inc.); vWF (Dako); Isolectin B4 (Vector Laboratories); SP-B (Upstate-Millipore); $\alpha$-smooth muscle actin (R\&D Systems); and MGP (provided by Reidar Wallin, Wake Forest University, Winston-Salem, North Carolina, USA). The nuclei were stained with DAPI (Sigma-Aldrich) (38). Cultured cells were grown in chamber slides and fixed in $4 \%$ paraformaldehyde for 30 minutes, permeabilized with $0.1 \%$ Triton $\mathrm{X}-100$, and blocked with $1 \%$ goat serum and $1 \%$ BSA in TBS. The cells were then immunostained using the same protocol as the tissues.

Vessel density. Vessel density was performed as previously described $(16,39)$. Paraffin blocks with embedded vessels were cut into 6 - $\mu \mathrm{m}$-thick cross sections, which were immunostained for the $\mathrm{vWF}$ factor as described above. Images were acquired with an inverted Zeiss Axiovert 200 microscope (Carl Zeiss MicroImaging Inc.). Only capillaries oriented perpendicular to the plane of sectioning were counted. Capillary density was calculated by dividing the total number of capillaries on the slides by the area of the stained sections in $\mathrm{mm}^{2}$ and then averaged.

Proliferation assays. HAECs were seeded in 24-well plates at a density of 100,000 cells per well, allowed to attach for 4 to 6 hours, and treated as indicated in the Results. ${ }^{3} \mathrm{H}$-Thymidine was added at $1 \mu \mathrm{Ci} / \mathrm{ml}$ for 4 days, and ${ }^{3} \mathrm{H}$-thymidine incorporation was determined as previously described (35).

Luciferase assays. Luciferase assays were performed as described previously and normalized to Renilla luciferase $(18,35)$. Luciferase and Renilla luciferase activities were determined using an AutoLumat LB953 luminometer (PerkinElmer Life Sciences), and the luciferase activity was expressed as mean \pm SD from quadruplicate transfections after normalization to Renilla luciferase activity.

Coimmunoprecipitation and cross-linking. Coimmunoprecipitation of BMP-7 and N-FLAG-MGP was performed as described previously (1). BMP-7 (100 ng) was added to $1 \mathrm{ml}$ culture medium from BAECs collected 24 hours after transfection of the N-FLAG-MGP construct or empty plasmid. Immunoprecipitation was performed using anti-BMP-7 antibodies $(1 \mu \mathrm{g} / \mathrm{ml}$; R\&D Systems), and immunoblotting was performed using antiFLAG antibodies as described above. Alternatively, immunoprecipitation and immunoblotting were performed using anti-FLAG and anti-BMP-4 antibodies, respectively.

Serum-free-conditioned media from transfected HEK293 cells were used in the cross-linking experiments. Conditioned medium was mixed with BMP-4 and chemically cross-linked with disuccinimidyl suberate as described previously (40). The cross-linked products were analyzed by immunoblotting and/or protein staining.

Statistics. Data were analyzed for statistical significance by ANOVA with post-hoc Tukey's analysis. The analyses were performed using GraphPad Instat, version 3.0 (GraphPad Software). Data represent mean \pm SD. $P$ values of less than 0.05 were considered significant, and experiments were repeated a minimum of 3 times.

\section{Acknowledgments}

Funding for this work was provided in part by NIH grants HL30568 and HL81397 and the American Heart Association (Western Affiliate and National Center).

Received for publication April 20, 2011, and accepted in revised form May 25, 2011.

Address correspondence to: Kristina I. Boström or Yucheng Yao, Division of Cardiology, David Geffen School of Medicine at UCLA, Box 951679, Los Angeles, California 90095-1679, USA. Phone: 310.794.4417; Fax: 310.206.8553; E-mail: kbostrom@mednet.ucla. edu (K.I. Boström), yyao@mednet.ucla.edu (Y. Yao). 
1. Zebboudj AF, Imura M, Bostrom K. Matrix GLA protein, a regulatory protein for bone morphogenetic protein-2. J Biol Chem. 2002;277(6):4388-4394.

2. Yao Y, Shahbazian A, Bostrom KI. Proline and gamma-carboxylated glutamate residues in matrix Gla protein are critical for binding of bone morphogenetic protein-4. Circ Res. 2008;102(9):1065-1074

3. Wallin R, Cain D, Hutson SM, Sane DC, Loeser R. Modulation of the binding of matrix Gla protein (MGP) to bone morphogenetic protein-2 (BMP-2). Thromb Haemost. 2000;84(6):1039-1044.

4. Luo G, et al. Spontaneous calcification of arteries and cartilage in mice lacking matrix GLA protein. Nature. 1997;386(6620):78-81.

5. Speer MY, et al. Smooth muscle cells give rise to osteochondrogenic precursors and chondrocytes in calcifying arteries. Circ Res. 2009;104(6):733-741.

6. Yao Y, Nowak S, Yochelis A, Garfinkel A, Bostrom KI. Matrix GLA protein, an inhibitory morphogen in pulmonary vascular development. J Biol Chem. 2007;282(41):30131-30142.

7. Munroe PB, et al. Mutations in the gene encoding the human matrix Gla protein cause Keutel syndrome. Nat Genet. 1999;21(1):142-144.

8. Parmar H, Blaser S, Unger S, Yoo SJ, Papsin B Petrified ears in a patient with Keutel syndrome: temporal bone CT findings. Pediatr Radiol. 2006 36(3):241-243.

9. David L, Feige JJ, Bailly S. Emerging role of bone morphogenetic proteins in angiogenesis. Cytokine Growth Factor Rev. 2009;20(3):203-212.

10. Govani FS, Shovlin CL. Hereditary haemorrhagic telangiectasia: a clinical and scientific review. Eur J Hum Genet. 2009;17(7):860-871.

11. Urness LD, Sorensen LK, Li DY. Arteriovenous malformations in mice lacking activin receptor-like kinase-1. Nat Genet. 2000;26(3):328-331.

12. Sadick H, Naim R, Gossler U, Hormann K, Riedel F. Angiogenesis in hereditary hemorrhagic telangiectasia: VEGF165 plasma concentration in correlation to the VEGF expression and microvessel density. Int J Mol Med. 2005;15(1):15-19.

13. Sadick H, et al. Does the genotype of HHT patients with mutations of the ENG and ACVRL1 gene correlate to different expression levels of the angiogenic factor VEGF? Int J Mol Med. 2008;22(5):575-580.

14. Shao ES, Lin L, Yao Y, Bostrom KI. Expression of vascular endothelial growth factor is coordinately regulated by the activin-like kinase receptors 1 and 5 in endothelial cells. Blood. 2009; 114(10):2197-2206
15. Yao Y, et al. Inhibition of bone morphogenetic proteins protects against atherosclerosis and vascular calcification. Circ Res. 2010;107(4):485-494.

16. Murphy PA, et al. Endothelial Notch4 signaling induces hallmarks of brain arteriovenous malformations in mice. Proc Natl Acad Sci U S A. 2008; 105(31):10901-10906.

17. Zhou L, Lim L, Costa RH, Whitsett JA. Thyroid transcription factor-1, hepatocyte nuclear factor3beta, surfactant protein B, C, and Clara cell secretory protein in developing mouse lung. J Histochem Cytochem. 1996;44(10):1183-1193.

18. Yao Y,ZebboudjAF, Shao E, Perez M, Bostrom K. Regulation of bone morphogenetic protein- 4 by matrix GLA protein in vascular endothelial cells involves activin-like kinase receptor 1. J Biol Chem. 2006; 281(45):33921-33930.

19. Yao Y, et al. High-density lipoproteins affect endothelial BMP-signaling by modulating expression of the activin-like kinase receptor 1 and 2. Arterioscler Thromb Vasc Biol. 2008;28(12):2266-2274.

20. David L, et al. Bone morphogenetic protein- 9 is a circulating vascular quiescence factor. Circ Res. 2008; 102(8):914-922.

21. Margraf LR, et al. Cloning and tissue-specific expression of the cDNA for the mouse Clara cell $10 \mathrm{kD}$ protein: comparison of endogenous expression to rabbit uteroglobin promoter-driven transgene expression. Am J Respir Cell Mol Biol. 1993;9(3):231-238.

22. Funaki $H$, et al. Localization and expression of AQP5 in cornea, serous salivary glands, and pulmonary epithelial cells. Am J Physiol. 1998; 275(4 pt 1):C1151-C1157.

23. Simic P, Vukicevic S. Bone morphogenetic proteins in development and homeostasis of kidney. Cytokine Growth Factor Rev. 2005;16(3):299-308.

24. Schrijvers BF, Flyvbjerg A, De Vriese AS. The role of vascular endothelial growth factor (VEGF) in renal pathophysiology. Kidney Int. 2004; 65(6):2003-2017

25 . Srinivasan $\mathrm{S}$, et al. A mouse model for hereditary hemorrhagic telangiectasia (HHT) type 2. Hum Mol Genet. 2003;12(5):473-482.

26. Herve $\mathrm{P}$, et al. Pulmonary vascular disorders in portal hypertension. Eur RespirJ. 1998;11(5):1153-1166.

27. Palaniswamy C, Sekhri A, Aronow WS, Kalra A, Peterson SJ. Association of warfarin use with valvular and vascular calcification: a review. Clin Cardiol. 2011;34(2):74-81.

28. Tarif $\mathrm{N}$, et al. Congenital renal arteriovenous malformation presenting as severe hypertension.
Nephrol Dial Transplant. 2002;17(2):291-294.

29. Ziani M, et al. Renal arteriovenous malformation requiring surgery in Rendu-Osler-Weber disease (hereditary hemorrhagic telangiectasia). JUrol. 2000; 164(4):1292-1293.

30. Di Gennaro L, et al. Asymptomatic microhematuria: an indication of hereditary hemorrhagic telangiectasia? J Urol. 2005;173(1):106-109.

31. Yao Y, et al. Inhibition of bone morphogenetic proteins protects against atherosclerosis and vascular calcification. Circ Res. 2010;107(4):485-494.

32. Medici D, et al. Conversion of vascular endothelial cells into multipotent stem-like cells. Nat Med. 2010; 16(12):1400-1406.

33. Lee $\mathrm{H}$, et al. Role for peroxisome proliferator-activated receptor alpha in oxidized phospholipidinduced synthesis of monocyte chemotactic protein- 1 and interleukin- 8 by endothelial cells. Circ Res. 2000;87(6):516-521.

34. Mundel P, et al. Rearrangements of the cytoskeleton and cell contacts induce process formation during differentiation of conditionally immortalized mouse podocyte cell lines. Exp Cell Res. 1997; 236(1):248-258

35. Bostrom K, Zebboudj AF, Yao Y, Lin TS, Torres A. Matrix GLA protein stimulates VEGF expression through increased transforming growth factorbeta1 activity in endothelial cells.J Biol Chem. 2004; 279(51):52904-52913.

36. Bostrom K, Tsao D, Shen S, Wang Y, Demer LL. Matrix GLA protein modulates differentiation induced by bone morphogenetic protein-2 in C3H10T1/2 cells. J Biol Chem. 2001;276(17):14044-14052.

37. Qiao JH, et al. Pathology of atheromatous lesions in inbred and genetically engineered mice. Genetic determination of arterial calcification. Arterioscler Thromb. 1994;14(9):1480-1497.

38. Bostrom KI, Jumabay M, Matveyenko A, Nicholas SB, Yao Y. Activation of vascular bone morphogenetic protein signaling in diabetes mellitus. Circ Res. 2010;108(4):446-457.

39. Chung AW, et al. Reduced expression of vascular endothelial growth factor paralleled with the increased angiostatin expression resulting from the upregulated activities of matrix metalloproteinase- 2 and -9 in human type 2 diabetic arterial vasculature. Circ Res. 2006;99(2):140-148.

40. Piccolo S, Sasai Y, Lu B, De Robertis EM. Dorsoventral patterning in Xenopus: inhibition of ventral signals by direct binding of chordin to BMP-4. Cell. 1996;86(4):589-598. 